www.nature.com/pj

\title{
Photo-optical properties of poly(oxadiazole-imide)s containing naphthalene rings
}

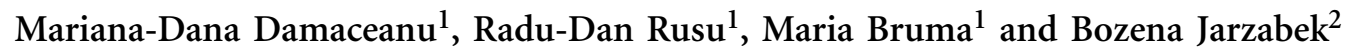 \\ Two series of poly(oxadiazole-imide)s based on naphthalene-containing anhydrides and aromatic diamines containing preformed \\ oxadiazole rings have been synthesized and their properties studied and compared. One series contains four polymers: two of \\ them are based on naphthalene-1,4,5,8-tetracarboxylic dianhydride and the other two are based on bis(ketonaphthalic- \\ anhydride). The other series contains four copolymers based on mixtures of these dianhydrides with hexafluoroisopropylidene- \\ diphthalic anhydride. The thermal stability of these polymers and copolymers and their photo-optical properties in solution and \\ solid state have been investigated.
}

Polymer Journal (2010) 42, 663-669; doi:10.1038/pj.2010.49; published online 16 June 2010

Keywords: fluorescence; polyimides; thermal properties; UV-vis spectroscopy

\section{INTRODUCTION}

Aromatic polyimides containing five-member imide rings have been extensively investigated in both industrial and government laboratories. The investigations have resulted in a large number of structureproperty correlations and a variety of different commercial products. These polyimides generally exhibit excellent thermal and thermooxidative stability, and outstanding mechanical and electrical properties. Consequently, they have been used as adhesives, matrix resins, fibers, films, membranes, foams and so on. ${ }^{1-4}$ Polyimides containing sixmember imide rings possessing naphthylimide structure have received little attention primarily due to the inability of obtaining soluble precursors for fabrication. Previous work on six-member polyimides has shown that the polymer system exhibited excellent thermal and thermooxidative resistance and very good hydrolytic stability in highly corrosive basic and acidic media. Moreover, polyimides based on naphthalene-1,4,5,8-tetracarboxylic acid dianhydride (NTDA) are of considerable interest due to easy accessibility of the starting monomers. NTDA is a widely available dianhydride showing the highest electrophilic reactivity among naphthalene tetracarboxylic dianhydrides $^{5-7}$ More recently, the naphthalene unit has been used as a component of $\pi$-conjugated copolymers of phenylenevinylene, fluorene, thiophene, carbazole and so on. The principal purpose of them was the development of an emissive material in organic light-emitting diodes. $^{8}$

On the other hand, aromatic polymers containing 1,3,4-oxadiazole ring in the main chain are also well known for their high thermal resistance in oxidative atmosphere, good hydrolytic stability, low dielectric constant and tough mechanical properties. ${ }^{9,10}$ There is currently much research directed towards the discovery of new blue light-emitting polymers, with characteristics of high efficiency and high reliability. For such purpose, poly(1,3,4-oxadiazole)s are of great interest due to the electron-withdrawing character of the 1,3,4-oxadiazole ring that can facilitate the injection and transport of electrons. ${ }^{11}$

We considered it interesting to synthesize two series of polyimides and copolyimides containing both oxadiazole and naphthalene units in the main chain, so that the resulting polymers have better thermal and thermooxitative stability and efficient photoluminescent and electron-transporting properties for future use in polymer lightemitting diodes. In this study, we investigated their thermal stability and photo-optical properties.

\section{EXPERIMENTAL PROCEDURE}

Monomers

Two aromatic diamines containing oxadiazole rings, namely, 2,5-bis [4-( $p$ aminophenoxy)-phenylene]-1,3,4-oxadiazole and 2,5-bis[4-(m-aminophenoxy)phenylene]-1,3,4-oxadiazole, have been prepared by a known procedure, ${ }^{12,13}$ starting from 4-fluorobenzoic acid and hydrazine hydrate, which first reacted in polyphosphoric acid to produce 2,5-bis( $p$-fluorophenyl)-1,3,4-oxadiazole, which further reacted with $p$ - or $m$-aminophenol.

The NTDA and hexafluoroisopropylidene-diphthalic dianhydride (6FDA) were purchased from Aldrich (Steinheim, Germany) and purified by recrystallization from glacial acetic acid and washed thoroughly with anhydrous diethylether.

The bis(ketonaphthalic-anhydride) was synthesized by Friedel-Crafts reaction, starting from isophthalic acid chloride and acenaphthene, following a published procedure. ${ }^{14,15}$

\section{Polymers}

Poly(naphthalene-imide)s, I, have been prepared by solution polycondensation reaction at high temperature of equimolar amounts of aromatic diamines containing oxadiazole rings with naphthalene-1,4,5,8-tetracarboxylic dianhydride

1'Petru Poni' Institute of Macromolecular Chemistry, Romanian Academy, lasi, Romania and ${ }^{2}$ Center of Polymer and Carbon Materials, Polish Academy of Sciences, Zabrze, Poland

Correspondence: Dr M-D Damaceanu, 'Petru Poni' Institute of Macromolecular Chemistry, Romanian Academy, Aleea Grigore Ghica Voda, 41A, lasi 700487, Romania. E-mail: damaceanu@icmpp.ro

Received 3 March 2010; revised 28 April 2010; accepted 2 May 2010; published online 16 June 2010 
or bis(ketonaphthalic-anhydride) to produce polyimides Ia-Id, or with a mixture 1:1 of 6FDA and naphthalene-1,4,5,8-tetracarboxylic dianhydride/ bis(ketonaphthalic-anhydride) to obtain copolyimides Ie-Ih. The polycondensation reaction was carried out in $N$-methylpyrrolidinone (NMP), in the presence of benzoic acid as catalyst, at a concentration of $10-12 \%$ total solids, as shown in Scheme 1. Their detailed synthesis has been reported elsewhere. ${ }^{16,17}$

\section{Preparation of polymer films}

Very thin films of polymers Id, If and Ih have been prepared on quartz substrates by spin-coating method using $1 \%$ polymer solution in $\mathrm{CHCl}_{3}$. All the films were heated at $50{ }^{\circ} \mathrm{C}$ to remove the residual solvent. The thickness of the films has been measured using an interference microscope. For the thickest film, Id, the value of its thickness has been also verified by ultraviolet visible (UV-Vis)-near-infrared reflectance measurements, where the thickness interferences were seen in the optical transmission and reflectivity spectra.

\section{Measurements}

Average-molecular weights were measured by means of gel permeation chromatography using a Waters gel permeation chromatography apparatus (Waters Corp., Milford, MA, USA), provided with refraction and UV photodiode array detectors and Shodex column (Waters Corp.). Measurements were carried out with polymer solutions having $2 \%$ concentration, and by using dimethylformamide/ $0.1 \mathrm{~mol} \mathrm{NaNO}_{3}$ as solvent and eluent, with a rate of $0.6 \mathrm{ml} \mathrm{min}^{-1}$. Polystyrene standards of known molecular weight in solution of dimethylformamide/ 0.1 mol $\mathrm{NaNO}_{3}$ were used for calibration.

The inherent viscosities of the polymers were determined at $20^{\circ} \mathrm{C}$, by using NMP-polymer solutions of $0.5 \mathrm{~g}$ per $100 \mathrm{ml}$ concentration, with an Ubbelohde viscometer (Schott \& Gen. Glasswerk, Mainz, Germany).

The thermal stability of the polymers was investigated by thermogravimetric analysis using an MOM derivatograph (MOM, Budapest, Hungary), operating at a heating rate of $12{ }^{\circ} \mathrm{C} \mathrm{min}^{-1}$, in air, from room temperature to $750{ }^{\circ} \mathrm{C}$. The onset on the thermogravimetric curve was considered to be the beginning of decomposition or the initial decomposition temperature. The temperature of maximum rate of decomposition, which is the maximum signal in differential thermogravimetry curves, was also recorded.

The glass transition temperature $\left(T_{\mathrm{g}}\right)$ of the precipitated polymers was determined by using a differential scanning calorimetry $12 \mathrm{E}$ calorimmeter (Mettler-Toledo, Greifensee, Switzerland). Approximately 3-8 mg of each polymer were crimped in aluminum pans and run in nitrogen with a heatcool-heat profile from room temperature to $350{ }^{\circ} \mathrm{C}$ at $10{ }^{\circ} \mathrm{C} \mathrm{min}-1$. The midpoint temperature of the change in slope of the differential scanning calorimetry signal of the second heating cycle was used to determine the glass transition temperature values of the polymers.

Optical transmission and fundamental reflectivity measurements were performed at room temperature, using two-beam UV-Vis-near-infrared reflectance spectrophotometer JASCO V-570 (JASCO, Cremella, Italy), within a wide spectral interval $200-2500 \mathrm{~nm}$. During the reflectivity measurements, a special two-beam reflectance arrangement was used with an $\mathrm{Al}$ mirror in the reference beam as a reflectance standard. Temperature dependence (from $25^{\circ} \mathrm{C}$ to $250^{\circ} \mathrm{C}$ ) of the film's absorption have been investigated with the special high temperature control equipment of JASCO spectrophotometer.

The photoluminescence (PL) spectra of polyimides were registered with Perkin Elmer LS 55 apparatus (Perkin Elmer, Warsaw, Poland), by using very diluted polymer solutions $\left(10^{-5} \mathrm{M}\right)$ or very thin polymer films.

\section{RESULTS AND DISCUSSION}

The polyimides studied here contain naphthalene units and oxadiazole rings in the main chain. Polycondensation reaction of equimolar amounts of aromatic oxadiazole-diamines with NTDA with bis(ketonaphthalic-anhydride), in NMP in the presence of benzoic acid as catalyst, yielded polyimides Ia-d after heating the intermediate polyamidic acids at high temperature, as shown in Scheme 1. The resulting polyimide solutions in NMP were used partly to cast thin films and partly to isolate the solid polymer by precipitation into water. Polyimides Ic and Id were soluble in NMP and their solutions were stable when stored for a long time (many months) at room temperature, while polyimides Ia and Ib separated from NMP solutions during the imidization process and were completely insoluble even by heating at reflux. In order to obtain soluble polyimides with NTDA, a mixture of this dianhydride with 6FDA was used in the polycondensation reaction with the diamino-oxadiazoles. The resulting copolyimides, Ie and If (Scheme 1) containing naphthalene and flexible hexafluoroisopropylidene $(6 \mathrm{~F})$ groups were soluble in polar amidic solvents and their solutions gave flexible films when spread onto glass plates. Also, the 6FDA was used in mixture 1:1 with bis(ketonaphthalic-anhydride) in the polycondensation with diamino-oxadiazoles to obtain copolyimides Ig and $\mathbf{I h}$ with the aim to increase the solubility and the thermal stability of the polymers, thus improving their high performance properties.

All the oxadiazole-containing poly(naphthaleneimide)s, except Ia and Ib, were soluble in aprotic amidic solvents such as NMP, dimethylacetamide or dimethylformamide, and most of them even in less polar solvents such as chloroform or tetrahydrofurane. The good solubility of these polyimides compared with that of related polyimides, based only on NTDA, is explained mainly by the presence of meta-catenated phenylene rings connected to carbonyl groups coming from bis(ketonaphthalicanhydride) monomer, and/or of flexible $6 \mathrm{~F}$ groups, respectively.

The molecular weights of the polyimides Ic-h were measured by gel permeation chromatography using polystyrene standards. The molecular weight values $M_{\mathrm{w}}$ are in the range of 32 700-201 700 Dalton; $M_{\mathrm{n}}$ in the range of 22600-139800 Dalton and polydispersity $M_{\mathrm{w}} / M_{\mathrm{n}}$ in the range of 1.44-1.82. As can be seen from these data, the present polymers have fairly high values of molecular weight and very narrow molecular weight distribution. It should be noted that gel permeation chromatography measurements using polystyrene standards provide only a crude estimate of molecular weights and not an accurate evaluation.

The inherent viscosity values of oxadiazole-containing poly (naphthaleneimide)s Ia-Ih, were in the range of $0.2-0.45 \mathrm{dl} / \mathrm{g}$. The low values of the viscosity of the present polymers can be explained by the lower electrophilic reactivity of six-membered anhydride rings as compared with their five-membered analogs. Comparable values of viscosity have been obtained by other authors for similar polyimides made from the same dianhydride but with other diamines, which clearly proved that the viscosity of the resulting poly(naphthaleneimide)s depends strongly on the structure of the monomers and the reaction conditions. ${ }^{18}$ Here, we intended to use eco-friendly reaction conditions as much as possible, avoiding the utilization of the most frequent solvent used in the synthesis of poly(naphthaleneimide)s, which is $m$-cresol, that has a very bad smell and is very dangerous for health compared with NMP.

\section{Thermal properties}

All these polyimides are highly thermostable, as evaluated by thermogravimetric analysis, their initial decomposition temperature $\left(T_{\mathrm{d}}\right)$ being above $430^{\circ} \mathrm{C}$ (Table 1). The polyimides Ia-d begin to decompose at $430-470^{\circ} \mathrm{C}$, while those containing $6 \mathrm{~F}$ groups, Ie-h, start their decomposition at $445-470^{\circ} \mathrm{C}$, which shows that the thermal stability was slightly increased by introducing of $6 \mathrm{~F}$ groups. The temperature of $10 \%$ weight loss is in the range of $453-500^{\circ} \mathrm{C}$ for those containing only naphtalene and oxadiazole units, and in the range of $490-520^{\circ} \mathrm{C}$ for those containing $6 \mathrm{~F}$ groups as well, which shows that the latter ones decompose at higher temperature than the former. The temperature of the maximum decomposition rate as evidenced by differential thermogravimetry curves is above $480^{\circ} \mathrm{C}$. These data 


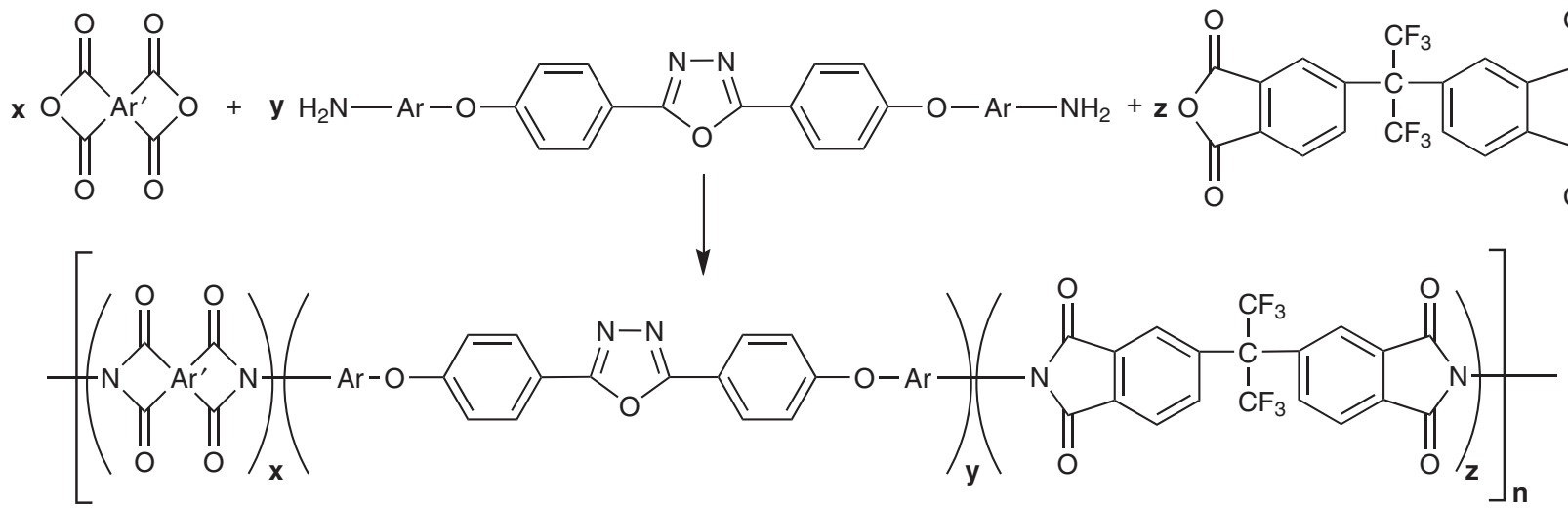

la: $x: y: z=1: 1: 0$;<smiles>[Li]c1ccc(I)cc1</smiles>

$A r^{\prime}=$<smiles>Cc1ccc(C)c2ccccc12</smiles>

lb: $x: y: z=1: 1: 0$;<smiles>[Li]c1cccc(I)c1</smiles><smiles>[Mg]=C1CCCC1</smiles><smiles>Cc1ccc(C)c2ccccc12</smiles>

Ic: $x: y: z=1: 1: 0$;<smiles>Brc1ccc(I)cc1</smiles>

$A r^{\prime}=$<smiles>Cc1cccc2ccccc12</smiles><smiles>Cc1cccc(C(=O)c2ccc(C)c3ccccc23)c1</smiles>

Id: $x: y: z=1: 1: 0$<smiles>Brc1cccc(I)c1</smiles><smiles>[Mg]=[Ti]</smiles><smiles>Cc1cccc2ccccc12</smiles><smiles>Cc1cccc(C(=O)c2ccc(C)c3ccccc23)c1</smiles>

le: $x: y: z=1: 2: 1$<smiles>Brc1ccc(I)cc1</smiles><smiles>[Te]=[Te]</smiles><smiles>Cc1ccc(C)c2ccccc12</smiles>

If: $x: y: z=1: 2: 1$<smiles>Brc1cccc(I)c1</smiles><smiles>C1=[Bi]CCCCC1</smiles><smiles>Cc1ccc(C)c2ccccc12</smiles>

Ig: $x: y: z=1: 2: 1$;<smiles>Brc1ccc(I)cc1</smiles>

$A r^{\prime}=$<smiles>c1ccc2ccccc2c1</smiles><smiles>CC(=O)c1cccc(C(=O)c2ccc(C)c3ccccc23)c1</smiles>

Ih: $x: y: z=1: 2: 1$<smiles>Brc1cccc(I)c1</smiles><smiles>[Mg]=[Ti]</smiles><smiles>Cc1ccc(C)c2ccccc12</smiles><smiles>Cc1cccc(C(=O)c2ccc(C)c3ccccc23)c1</smiles>

Scheme 1 Synthesis of the oxadiazole-containing poly(naphthaleneimide)s la-h.

show that all these polyimides have high thermal stability, similar with that of other polyimides based on the same diamino-oxadiazoles but without naphthalene units, ${ }^{19}$ and with that of polyimides based on the same bis(naphthalic anhydrides) but without oxadiazole rings. ${ }^{20,21}$
The glass transition temperature of the polyimides was evaluated by differential scanning calorimetry. All these polymers, except Ia, exhibit a glass transition in the range of $190-318^{\circ} \mathrm{C}$ (Table 1$)$. The polymer Ib shows the highest $T_{\mathrm{g}}\left(318^{\circ} \mathrm{C}\right)$ due to the lack of any flexible groups. 
Table 1 Thermal properties of the polyimides la-h

\begin{tabular}{lcccccccc}
\hline Polymer & la & lb & Ic & Id & le & If & lg & lh \\
\hline$T_{\mathrm{g}}\left({ }^{\circ} \mathrm{C}\right)$ & Not detected & 318 & 195 & 190 & 296 & 265 & 245 & 195 \\
IDT $\left({ }^{\circ} \mathrm{C}\right)$ & 470 & 450 & 450 & 430 & 470 & 445 & 470 & 465 \\
\hline
\end{tabular}

$T_{\mathrm{g}}$, glass transition temperature measured by differential scanning calorimetry (DSC); initial decomposition temperature (IDT), onset temperature on thermogravimetric curve.

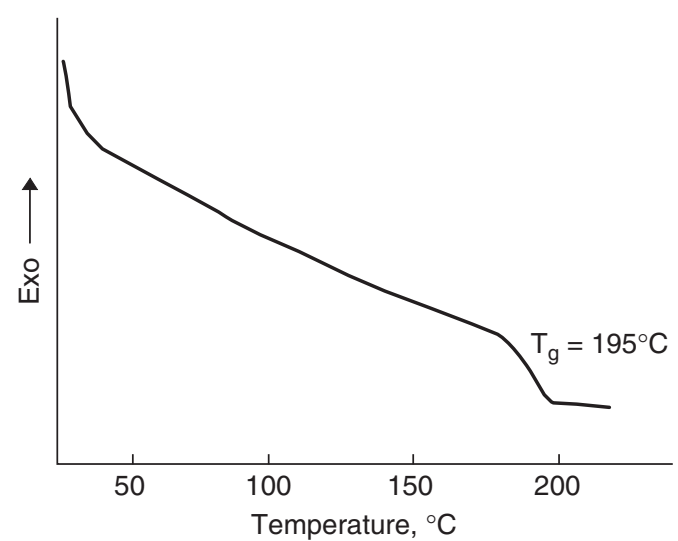

Figure 1 Differential scanning calorimetry curve of polyimide Ih.

The polyimides Ic and Id present lower $T_{\mathrm{g}}$ values compared with polymers Ia and Ib due to the presence of meta-catenation connected to a kinking carbonyl group that allows the segmental movement in the polymer chain. The introduction of $6 \mathrm{~F}$ groups in the copolymers Ie-h does not have a clear influence on $T_{\mathrm{g}}$ : in some cases $T_{\mathrm{g}}$ decreases (copolyimides Ie and If), whereas in other polymers it increases (copolyimides Ig and Ih). It can be seen that there is a large interval between $T_{\mathrm{g}}$ and decomposition temperature of these polyimides, which can be advantageous for their processing by thermoforming technique. A typical differential scanning calorimetry curve is shown in Figure 1.

\section{Photo-optical properties}

There is currently much interest in polymeric electroluminescent materials, particularly in those which are able to emit blue light, which is difficult to attain from the already known inorganic ones. ${ }^{22}$ In addition, the use of electroluminescent thin films made from highly thermostable polymers would avoid thermal degradation in the final device, while in service at elevated temperatures. The light-emitting ability of these polymers containing both oxadiazole and naphthylimide chromophores was assessed on the basis of the PL spectra, which were recorded for both polymer solutions and polymer films cast from $\mathrm{CHCl}_{3}$ solutions, after irradiation with UV light. Preliminary characterization of the photo-optical properties of the present polymers in solution showed that copolymers containing $m$-phenylene units in the diamine segment of the repeat unit exhibited the highest intensity of fluorescenece. ${ }^{16}$ Therefore, this paper reports an extensive investigation of the photo-optical properties of the polynaphthalenimides based on 2,5-bis[4-(m-aminophenoxy)-phenylene]-1,3,4-oxadiazole in solution and solid state. As polyimide Ib was not soluble in $\mathrm{CHCl}_{3}$, here we report the photo-optical properties of polynaphthylimides Id, If and Ih, in order to establish the optimal parameters for future OLED manufacturing based on such polymers.

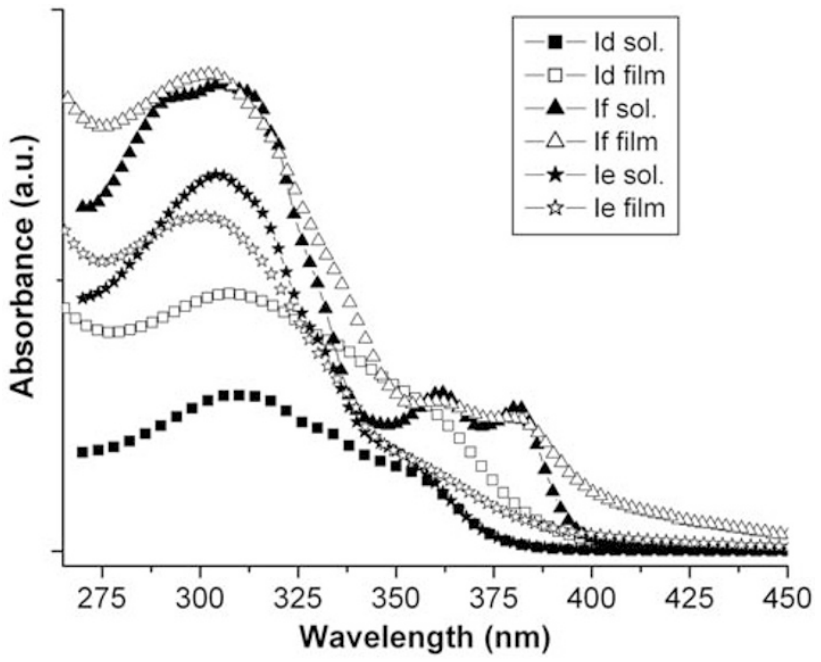

Figure 2 UV-absorption spectra in solution and film of polyimides Id, If and Ih.

Table 2 Optical properties of polynaphthaleneimides Id, If and Ih in solution and solid state

\begin{tabular}{|c|c|c|c|c|c|c|}
\hline \multirow[b]{2}{*}{ Polymer } & \multicolumn{3}{|c|}{ Solution } & \multicolumn{3}{|c|}{ Film } \\
\hline & $U V \lambda_{a b s}(n m)$ & $\begin{array}{c}\text { UV } \lambda_{\text {edge }} \\
(n m)\end{array}$ & $\mathrm{E}_{g}(\mathrm{eV})$ & $\begin{array}{c}U V \lambda_{a b s} \\
(n m)\end{array}$ & $\begin{array}{c}\text { UV } \lambda_{\text {edge }} \\
(n m)\end{array}$ & $\begin{array}{c}\mathrm{E}_{g} \\
(\mathrm{eV})\end{array}$ \\
\hline Id & $308,332^{s}, 355^{s}$ & 381 & 3.25 & 307 & 394 & 3.15 \\
\hline If & $306,360,381$ & 400 & 3.10 & $302,360,384$ & 403 & 3.07 \\
\hline Ih & $305,331^{s}, 355^{s}$ & 375 & 3.30 & 301 & 389 & 3.19 \\
\hline
\end{tabular}

$\lambda_{\text {abs }}$, wavelength of the maximum absorption peak; $\lambda_{\text {edge }}$, wavelength of the absorption edges of the optical absorption spectra; $E_{\mathrm{g}}$, energy band gap calculated from the ultraviolet (UV) absorption spectra; s, shoulder.

The proeminent feature in these materials is their extended conjugated $\pi$-system; such extension is mirrored by the electronic absorption spectrum. In Figure 2, the absorption spectra of dimethylacetamide solutions and cast films from $\mathrm{CHCl}_{3}$ solutions of the three polyimides are reported. It was found that polymers Id and Ih present one strong absorption peak at 305-308 nm and two shoulders at 331332 and $355 \mathrm{~nm}$, in dimethylacetamide solutions (Table 2). The absorption maxima at $305-308 \mathrm{~nm}$ of these polymers are mainly determined by the diphenyl-1,3,4-oxadiazole unit because the unsubstituted diphenyl-1,3,4-oxadiazole in hexane shows its absorption maximum at $284 \mathrm{~nm} .{ }^{13,23}$ The absorption shoulders at $331-332 \mathrm{~nm}$ and $355 \mathrm{~nm}$ are due to the absorption of bis(ketonaphthimide) segments. The polyimide If shows three strong UV absorption peaks, at $306 \mathrm{~nm}$ due to the presence of phenyloxadiazole chromophore, and 360 and $381 \mathrm{~nm}$ due to the chain segments containing naphthylimide chromophore. In films cast from $\mathrm{CHCl}_{3}$ solution, the absorption maxima of polyimides Id and Ih are centered at 307 and $301 \mathrm{~nm}$, respectively, being blue-shifted with respect to the absorption of the isolated molecules. The film of polymer If based on NTDA shows the main UV maximum at $302 \mathrm{~nm}$, and other two small peaks at 360 and $384 \mathrm{~nm}$. The small red-shift of the maximum from the highest wavelength in solid state as compared with solution for polymer If could be explained by negligible intermolecular interactions of the conjugated naphthylimide segments of the polymer chains. 
The absorbance spectra of solutions and thin films allow us to compare the position of absorption bands $\lambda_{\mathrm{abs}}$, as seen in Table 2 . The absorption edge, being a long-wavelength wing of the longest-wavelength band of the spectrum, moves to a longer wavelength (smaller energy) for the polymer films when compared with the edge of solution of the same polymer. This means that conformation of polymer chain can be different depending upon the surroundings. ${ }^{24}$

The energy band gap $\left(E_{\mathrm{g}}\right)$ could be estimated from the following equation:

$$
E_{\mathrm{g}}=h \times c / \lambda_{\text {edge }}
$$

where $h$ is the Planck constant, $c$ is the light velocity, and $\lambda_{\text {edge }}$ is the wavelength of the absorption edges of the optical absorption spectra. Table 2 shows $E_{\mathrm{g}}$ values of the polyimides Id, If and Ih in solution and solid state. The $E_{\mathrm{g}}$ values are influenced by the nature of dianhydride used for the synthesis. Thus, the $E_{\mathrm{g}}$ values of polyimides based on NTDA are smaller than that of polyimides based on bis(ketonaphthimide) due to the more aggregated conformation of polymer main chains of the former. ${ }^{25}$ Also, the introduction of $6 \mathrm{~F}$ groups in the polymer chains results in slightly higher $E_{\mathrm{g}}$ values, which means that the packing of the macromolecules was somewhat disturbed. These data are well correlated with the solubility and overall shape of the corresponding macromolecules observed in molecular modelling of these polymers. This simple method allowed estimating and then comparing the energy gaps for investigated polymers in the form of solution and thin film, as it is gathered in Table 2.

The real, exact values of energy gaps of investigated thin films can be obtained from the edge of the absorption coefficient $\alpha$ (in $\mathrm{cm}^{-1}$ ) calculated, according to the formula given in the study by Jarzabek et al. ${ }^{26}$ on the basis of transmission $(T)$ and reflectivity $(R)$ measurements, taking into consideration the thickness $(d)$ of the film, as it is presented below in this work. Transmission and reflectivity spectra of the investigated thin films of polymers Id, If and Ih, within the spectral range $200-2500 \mathrm{~nm}$ and at room temperature, are shown in Figure 3.

The Kramers-Kronig analysis ${ }^{27}$ applied to the reflectance spectra of our polymer films yields the values of the refractive index, $n$, between 1.63 and 1.92, and for extinction coefficient, $k$, between 0.03 and 0.05 , as shown in Table 3. The obtained values of refractive index and extinction coefficient are rather typical for polymer films. ${ }^{28}$ Thickness interferences, seen in Figure 6, for the optical transmission and reflectivity spectra of the thickest film Id allowed to obtain its thickness of about $320 \mathrm{~nm}$. The films Id and Ih turned out to be too thin ( 80 and $100 \mathrm{~nm}$, respectively), so that we could not find any thickness interferences in their optical spectra (Figure 3 ).

The absorption coefficient $(\alpha)$ for all investigated films has been obtained on the basis of transmission and reflectivity measurements, according to the formula given in the study by Jarzabek et al. ${ }^{26}$ Usually, the square root dependence $\alpha \propto\left(E-E_{\mathrm{g}}\right)^{1 / 2}$ has been used to describe absorption edge of thin polymer films. ${ }^{29}$ The absorption edges of all investigated oxadiazole-containing polynaphthylimide films have been found to follow the power law $\alpha \propto\left(E-E_{\mathrm{g}}\right)^{2}$, typical for amorphous semiconductors. ${ }^{30}$ Structural disorder defect resulting from different lengths and orientations of polymer chains seems to be responsible for the amorphous character of the absorption edge of many polymers. This approach used for amorphous semiconductors has been also applied by us earlier to obtain energy gaps for amorphous polymer foils ${ }^{31}$ and thin films. ${ }^{28}$ The energy gaps $\left(E_{\mathrm{g}}\right)$ of investigated films were determined from the linear approximation of $(\alpha \times E)^{1 / 2}=f(E)$ dependence, known as the Tauc relation, ${ }^{32}$ at the energy range $E>E_{\mathrm{g}}$. The energy gap of these six-member polyimide

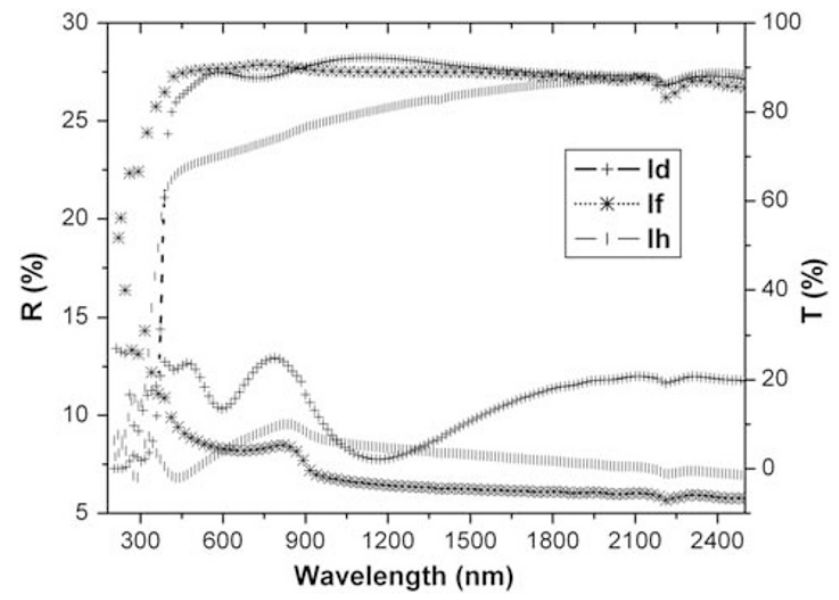

Figure 3 Transmission and reflectivity spectra of the thin films of polyimides Id, If and Ih.

Table 3 Optical parameters and thicknesses of the polyimide films Id, If and Ih taken from reflectance spectra

\begin{tabular}{lcccc}
\hline Polymer & $\begin{array}{c}\text { Refractive } \\
\text { index, } \mathrm{n}\end{array}$ & $\begin{array}{c}\text { Extinction } \\
\text { coefficient, } \mathrm{k}\end{array}$ & $\begin{array}{c}\text { Thickness, } \\
\mathrm{d}(\mathrm{nm})\end{array}$ & $\begin{array}{c}\text { Energy gap, } \\
\mathrm{E}_{\mathrm{g}}(\mathrm{eV})\end{array}$ \\
\hline Id & 1.92 & 0.03 & 320 & 3.04 \\
If & 1.63 & 0.04 & 80 & 2.77 \\
Ih & 1.72 & 0.05 & 100 & 2.95 \\
\hline
\end{tabular}

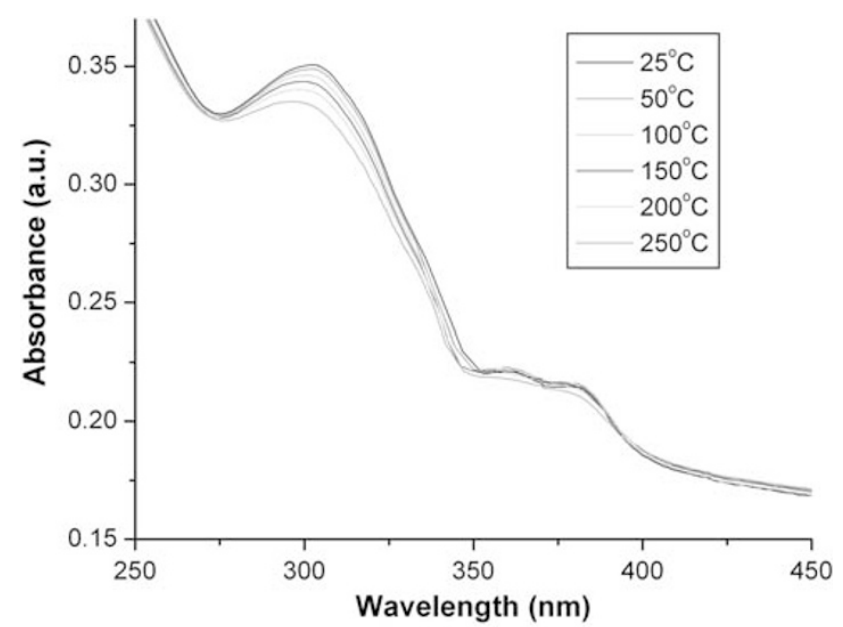

Figure 4 UV absorption spectra of polyimide If at different temperatures. A full color version of this figure can be found at Polymer Journal online.

films under study changes from $2.77 \mathrm{eV}$ for If to $3.04 \mathrm{eV}$ for Id (Table 3). The highest value of energy gap indicates rather short conjugated parts of the Id polymer chain, while for If, the presence of naphthylimide units in the polymer chain causes larger planarity with an increase of conjugated parts and therefore the energy gap decreases.

The UV-vis absorption spectroscopy has been used to monitor the changes in spectroscopic properties of polyimides Id, If and Ih during heating, from room temperature up to $250^{\circ} \mathrm{C}$, as well. Representative temperature dependence of absorption for one of the investigated films is shown in Figure 4. The results indicated that the investigated 
Table 4 Photo-optical properties of polyimides Id, If and Ih

\begin{tabular}{lccccc}
\hline & \multicolumn{3}{c}{ Solution } & & \multicolumn{3}{c}{ Film } \\
\cline { 5 - 6 } Polymer & $\lambda_{P L}(n m)$ & Stokes shift $(n m)$ & $\lambda_{P L}(n m)$ & Stokes shift $(n m)$ \\
\hline Id & 381,405 & 73 & & $398,421,446^{\text {s }}, 484$ & 91 \\
If & 374,398 & 68 & & $360,420,444^{\text {s }}, 484$ & 58 \\
Ih & 376 & 71 & & $385,419,446^{\text {s }}, 484$ & 84 \\
\hline
\end{tabular}

Abbreviations: $\lambda_{\mathrm{PL}}$, wavelength of the maximum photoluminescence $(\mathrm{PL})$ emission peak; $\mathrm{s}$, shoulder.

polyimides have a very good optical stability in the temperature range below the glass transition temperatures. The intensity of the main absorption bands slightly decreases with the increasing temperature (but less then 6\%) for all films. During heating, the position of absorption band almost did not change for the polymer film Id and moved very slightly to shorter wavelengths $(\sim 1.6 \mathrm{~nm})$ for the polymer film Ih. The shift of absorption band to the shorter wavelengths $(\sim 6.2 \mathrm{~nm}$ ) was clearly seen for the film If (Figure 4$)$, which may be the indication that this polymer chain conformation changed insignificantly with increasing temperature. All these data demonstrate that the present polynaphthylimide films could be used in devices in which the operating temperature is much higher than the room temperature.

A targeted use of the present polymers is as efficient as electroluminescent materials in light-emitting diodes. For such an application, two conditions have to be fulfilled: first, the polymer should show intensive PL and second, the polymer should be able to transport charge carriers. Therefore, the PL properties of the polymers in solution and solid state were studied to determine the color and to survey the intensity. By exciting at their maxima absorption wavelength, the polymers Id, If and Ih displayed the main emission maxima in the UV domain at 381,374 and $376 \mathrm{~nm}$, respectively. Polyimides Id and If presented one additional peak, in the violet domain, at 405 and $398 \mathrm{~nm}$, respectively. Polyimides Id and Ih presented a red-shift of the main emission maxima compared with polyimide If, probably due to the substitution of $m$-phenylene rings with oxygen in the dianhydride segment of the repeating unit: in the excited state the oxygen acts as a better bridge for the delocalization of the charge, because the position of the phenylene ring next to the oxygen determines the PL more significantly. ${ }^{13,33}$ The PL spectra of the films cast from $\mathrm{CHCl}_{3}$ solutions showed three maxima in the range of 360-398, 419-421 and 484-485 nm, and one shoulder in the range of $444-446 \mathrm{~nm}$ (Table 4). The red-shift of the main PL maximum in film (398 and $385 \mathrm{~nm}$ ) compared with solution (381 and 376) of the polymides Id and Ih, which contain oxygen bridges in the dianhydride segment of the structural unit, could be explained by negligible intermolecular interactions of the conjugated parts of the polymer chains. The film of copolymer If showed the main PL maximum at $360 \mathrm{~nm}$, being blue-shifted compared with solution $(374 \mathrm{~nm})$. Interestingly, although most conjugated polymers exhibit bathochromic shifts from solution to solid state, the emission spectra of polymers If exhibit hypsochromic shifts in thin films, which is indicative of a solid-state organization that disrupts the extent of conjugation. ${ }^{34}$ The small peaks at $419-421$ and $484-485 \mathrm{~nm}$, and the shoulder at $444-446 \mathrm{~nm}$ in the PL spectra of all polyimide films are due to the various degrees of aggregation and the excimer formation in the films, leading to PL quenching, emission band broadening and bathochromic shift. ${ }^{35}$ The PL spectra of the polyimides Id, If and Ih in solution and film are shown in Figure 5.

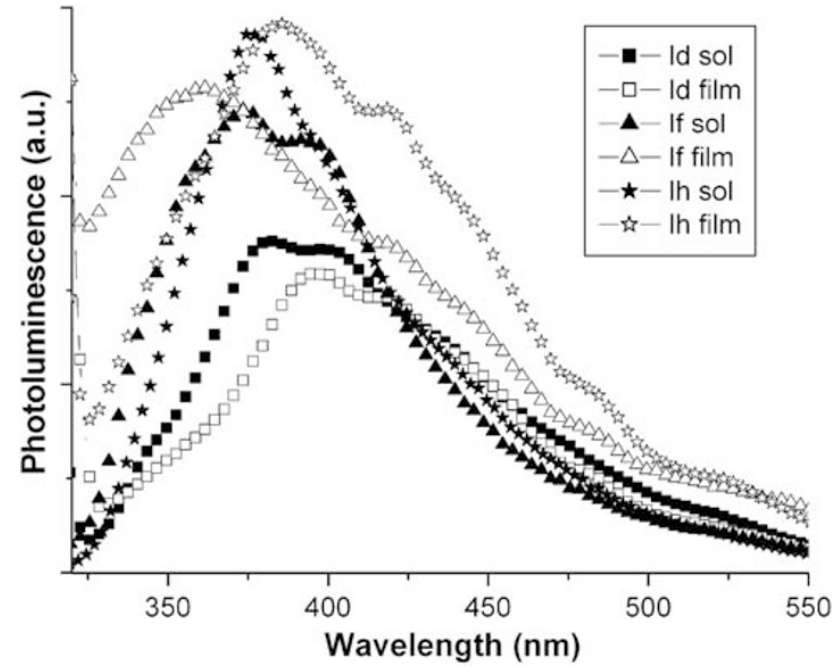

Figure 5 Photoluminescence spectra of polyimides Id, If and Ih.

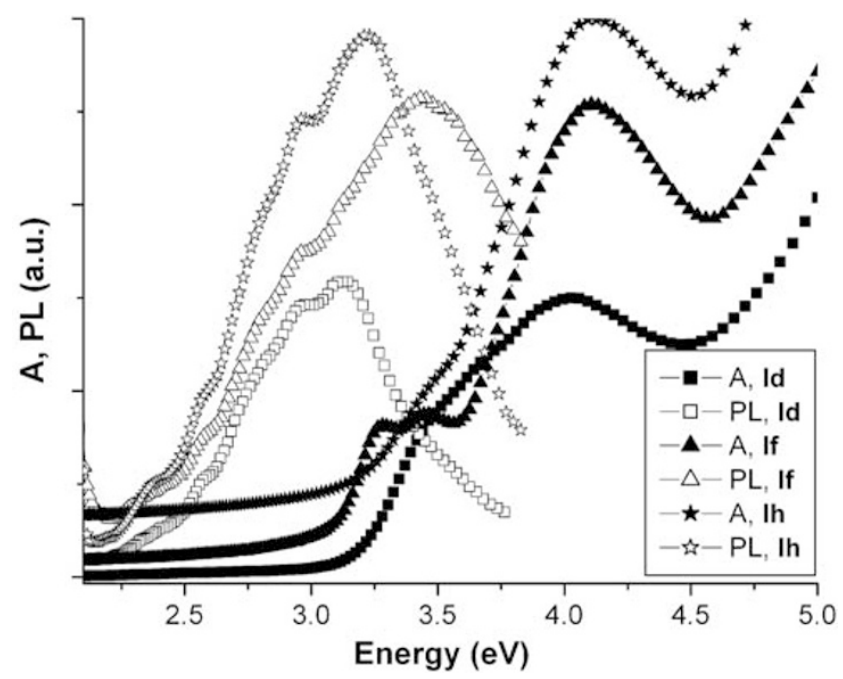

Figure 6 Absorption (A) and photoluminescence $(P)$ versus energy for polyimide films Id, If and Ih.

The Stokes shift (the difference between the main fluorescence and UV-vis peaks) of polymers Id, If and Ih in solution and solid state are of 58-91 nm (Table 4). It is known that if the Stokes shift is too small, the emission and absorption spectra will overlap more often. Then, the emitting light will be self-absorbed and the luminescence efficiency will decrease in the device. ${ }^{25}$ All these polynaphthylimides display high enough values of the Stokes shift for good luminescence efficiency. Absorption (A) spectra together with PL spectra as a function of energy are gathered in Figure 6 for polymer films Id, If and Ih. The Stokes shift obtained for the films of polymers Id and Ih are 0.88 and $0.86 \mathrm{eV}$, respectively. The smallest value of $0.67 \mathrm{eV}$ was obtained for the polymer If film.

\section{CONCLUSIONS}

Aromatic polyimides and copolyimides were obtained by polycondensation reaction of aromatic diamines containing oxadiazole ring with NTDA or with bis(ketonaphthalic-anhydride), or with a mixture of such a dianhydride and 6FDA. The polymers based only on NTDA 
were not soluble in organic solvents, whereas all the other polymers were easily soluble in polar amidic solvents and some of them in less polar and convenient solvents, such as tetrahydrofuran or $\mathrm{CHCl}_{3}$, allowing them to be processed in thin films and coatings. These sixmember polyimides are highly thermostable, their initial decomposition temperature being above $430^{\circ} \mathrm{C}$. The majority of these polymers do exhibit a $T_{\mathrm{g}}$ value, high enough $\left(190-318^{\circ} \mathrm{C}\right)$, but still with a large window between $T_{\mathrm{g}}$ and decomposition temperature, which may be useful for their processing by thermoforming techniques. In films cast from $\mathrm{CHCl}_{3}$ solution, the absorption maxima of polyimides based on bis(ketonaphthalic-anhydride) are blue-shifted with respect to the absorption of the isolated molecules. The film of polymer based on NTDA shows the main UV maximum at $302 \mathrm{~nm}$, and other two small peaks at 360 and $384 \mathrm{~nm}$. The small red-shift of the maximum from the highest wavelength in solid state as compared with solution could be explained by negligible intermolecular interactions of the conjugated naphthylimide segments of the polymer chains. The values of the refractive index, $n$, ranges between 1.63 and 1.92, and for extinction coefficient, $k$, between 0.03 and 0.05 , being typical for polymer films. The energy gaps of the films, following the Tauc relation, are found to change from 2.77 to $3.04 \mathrm{eV}$, depending on the length of conjugated part of the polymer chain. Excited with UV light, the polymer solutions exhibited emission in the UV domain at 374-381 nm and some of the polymers presented one additional peak, in the violet domain, at $398-405 \mathrm{~nm}$. The PL spectra of the films cast from $\mathrm{CHCl}_{3}$ solutions showed three maxima in the range of 360-398, 419-421 and 484-485 nm, and one shoulder in the range of 444$446 \mathrm{~nm}$. A red-shift of the main PL maximum in film compared with solution of the polyimides containing oxygen bridges in the dianhydride segment was observed. The main PL maximum of the polymer based on NTDA is blue-shifted compared with solution, indicative of a solid-state organization that disrupts the extent of conjugation. The Stokes shifts in solution and solid state are of 58-91 nm, high enough for a good luminescence efficiency. All the data presented here are very important from the point of view of possible applications in photoelectronic devices.

\section{ACKNOWLEDGEMENTS}

The financial support provided through Romanian Program TE is warmly acknowledged.

1 Sroog, C. E. Polyimides. Prog. Polym. Sci. 16, 561-694 (1991).

2 Feger, C. \& Franke, H. in Polyimides: Fundamentals and Applications (eds. Ghost, M. K. \& Mittal, K. L.) Ch. 24, 759-814 (Marcel Decker: New York, 1996).

3 Hergenrother, P. M. The use, design, synthesis, and properties of high performance/high temperature polymers: an overview. High Perform. Polym. 15, 3-45 (2003).

4 Jiang, L. Y., Wang, Y., Chung, T. S., Xiao, X. Y. \& Lai, J. Y. Polyimides membranes for pervaporation and biofuels separation. Prog. Polym. Sci. 34, 1135-1160 (2009).

5 Laughran, G. A. \& Arnold, F. E. Aromatic polynaphthalimides. Polym. Prep. 18, 831834 (1977).

6 Korshak, V. V. \& Rusanov, A. L. Novel trends in ladder polyheteroarylenes. J. Macromol. Sci., Part C: Polym. Rev. 21, 275-312 (1982).

7 Rusanov, A. L., Elshina, L. B., Bulyceva, E. G. \& Müllen, K. in Polymer Yearbook (eds. Pethrik, R. \& Zaikov, G.), Vol. 18, Ch. 1, 7-47 (Rapra Technology Ltd, Shropshire UK, 2004).
8 Akcelrud, L. Electroluminescent polymers. Prog. Polym. Sci. 28, 875-962 (2003).

9 Schulz, B., Bruma, M. \& Brehmer, L. Aromatic poly(1,3,4-oxadiazole)s as advanced materials. Adv. Mater. 9, 601-613 (1997).

$10 \mathrm{Kim}$, S. W., Shim, S. C., Jung, B. J. \& Shim, H. K. Synthesis and properties of new electroluminescent polymers possessing both hole and electron-transporting units in the main chain. Polymer 43, 4297-4305 (2002).

11 Ishii, J., Sunaga, T., Deguchi, S. \& Tsukioka, M. A deep-blue electroluminescence from 2,5-diphenyl-1,3,4-oxadiazole and polyfluorene copolymer end-capped with triphenylamine. High Perform. Polym. 21, 393-410 (2009).

12 Bruma, M., Schulz, B. \& Mercer, F. Polyamide copolymers containing hexafluoroisopropylene groups. J. Macromol. Sci. Part A: Pure Appl. Chem. 32, 259-286 (1995).

13 Iosip, M. D., Bruma, M., Robison, J., Kaminorz, Y. \& Schulz, B. Study of related poly(1,3,4-oxadiazole-amide)s containing silicon or hexafluoroisopropylidene groups in the main chain. High Perform. Polym. 13, 133-148 (2001).

14 Rusanov, A. L. Novel bis(naphthalic anhydrides) and their polyheteroarylenes with improved processability. Adv. Polym. Sci. 111, 115-175 (1994).

15 Korshak, V. V., Bulycheva, E. G., Shifrina, Z. B., Berlin, A. M., Shalikiani, M. O., Butskhrikidze, B. A., Rusanov, A. L., Mironov, G. S., Moskvichev, Yu.A., Timoshenko, G. N., Titov, V. I., Jedlinski, Z. \& Palivoda, A. New bis(naphthalic anhydrides) and polyheteroarylenes on their basis. Acta Polym. 39, 460-464 (1988).

16 Damaceanu, M. D., Rusu, R. D., Bruma, M. \& Rusanov, A. L. New thermally stable and organosoluble heterocyclic poly(naphthaleneimide)s. Polym. Adv. Technol. (e-pub ahead of print 2 August 2009; doi:10.1002/pat.1519).

17 Rusu, R. D., Damaceanu, M. D. \& Bruma, M. Comparative study of soluble poly(ketonaphthylimide)s. Rev. Roum. Chim. 54, 1015-1022 (2009).

18 Sek, D., Pijet, P. \& Wanic, A. Investigation of polyimides containing naphthalene units: 1. Monomer structure and reaction conditions. Polymer 33, 190-193 (1992).

19 Bruma, M. \& Damaceanu, M. D. Polyimides containing oxadiazole rings. Collect. Czech. Chem. Commun. 73, 1631-1644 (2008).

20 Bulycheva, E. G., Elshina, L. B., Askadskii, A. A., Rusanov, A. L., Doroshenko, Yu.E., Bespalova, T. A., Vlasov, V. M. \& Rogozhnikova, O.Yu. New Poly(naphthylimide)s. Polym. Sci. Ser. B 38, 353-355 (1996).

21 Rusanov, A. L., Krasnov, A. P., Bulycheva, E. G., Elshina, L. B., Svetlova, N. A. \& Doroshenko, Yu.E. Soluble polynaphthylimides processable by injection molding. Polym. Sci. Ser. B 39, 406-408 (1997).

22 Segura, J. L. The chemistry of electroluminescent organic materials. Acta Polym. 49, 319-344 (1998).

23 Hill, J. in Comprehensive Heterocyclic Chemistry (eds. Katritzky, A. R., \& Rees, C. W.), Vol. 6, Ch. 4, 427-446 (Pergamon Press, London, UK, 1984).

24 Sek, D., Iwan, A., Jarzabek, B., Kaczmarczyk, B., Kasperczyk, J., Azurak, M. Z., Domanski, M., Karon, K. \& Lapkowski, M. Hole transport triphenylamine-zomethine conjugated system: synthesis and optical, photoluminescence, and electrochemical properties. Macromolecules 41, 6653-6663 (2008).

25 Sun, Y. M. \& Wang, C. S. Synthesis and luminescent characteristics of novel phosphorus containing light-emitting polymers. Polymer 42, 1035-1045 (2001).

26 Jarzabek, B., Weszka, J., Burian, A. \& Pocztowski, G. Optical properties of amorphous thin films of the Zn-P system. Thin Solid Films 279, 204-208 (1996).

27 Fellman, J. \& Westerlund, T. Determination of the complex indices of refraction of glasses using Kramers-Krönig transformation. J. Non-Cryst. Solids 146, 165-174 (1992).

28 Jarzabek, B., Weszka, J., Domański, M., Jurusik, J. \& Cisowski, J. Optical studies of aromatic polyazomethine thin films. J. Non-Cryst. Solids 354, 856-862 (2008).

29 Rohlfing, F. \& Bradley, D. D. C. Non-linear stark effect in polyazomethine and poly(pphenylene-vinylene): the interconnection of chemical and electronic structure. Chem. Phys. 227, 133-151 (1998).

30 Mott, N. F. Conduction in non-crystalline systems I. Localized electronic states in disordered systems. Philos. Mag. 17, 1259-1268 (1968).

31 Jarzabek, B., Schab-Balcerzak, E., Chamenko, T., Sek, D., Cisowski, J. \& Volozhin, A. Optical properties of new aliphatic-aromatic co-polyimides. J. Non-Cryst. Solids 299-302, 1057-1061 (2002).

32 Tauc, J. \& Menth, A. States in the gap. J. Non-Cryst. Solids 8-10, 569-585 (1970).

33 Damaceanu, M. D. \& Bruma, M. Copolymer architectures containing donor and acceptor units for blue light-emitting diodes. J. Optoelectr. Adv. Mater. 10, 3086-3090 (2008).

34 Bouffard, J. \& Swager, T. M. Fluorescent conjugated polymers that incorporate substituted 2,1,3-benzooxadiazole and 2,1,3-benzothiadiazole units. Macromolecules 41, 5559-5562 (2008).

35 Zhan, X., Liu, Y., Wu, X., Wang, S. \& Zhu, D. New series of blue-emitting and electron-transporting copolymers based on fluorene. Macromolecules 35, 2529-2537 (2002). 